\title{
Width of adiabatic shear bands
}

\section{B. Dodd \& Y. Bai}

To cite this article: B. Dodd \& Y. Bai (1985) Width of adiabatic shear bands, Materials Science and Technology, 1:1, 38-40, DOI: 10.1179/mst.1985.1.1.38

To link to this article: http://dx.doi.org/10.1179/mst.1985.1.1.38

曲 Published online: 18 Jul 2013.

Submit your article to this journal $2 \pi$

III Article views: 26

Q View related articles $\asymp$

Citing articles: 28 View citing articles 
Width of adiabatic shear bands

An equation for the half-width of an adiabatic shear band is derived. With reference to the equation, the importance of thermal conductivity, temperature, and viscosity in determining the bandwidth are illustrated. It is shown that calculations of shear band width are fairly close approximations to those obtained experimentally. The apparent insensitivity of shear band width to the loading conditions is in agreement with experimental findings of other researchers.

$M S T / 156$

(C) 1985 The Institute of Metals. Manuscript received 17 February 1984; in final form 25 May 1984. This work was carried out by Dr Dodd in the Department of Engineering, University of Reading, Berkshire, and Professor Bai in the Institute of Mechanics, Chinese Academy of Sciences, Beijing, People's Republic of China.
B. Dodd
Y. Bai different processes in connection with which shear bands are found.

The applied strain rate and the thermal properties of the material, such as the specific heat and the thermal conductivity, are of fundamental importance to the appearance and the geometry of shear bands. Indeed, if it is accepted that increasing the strain rate normally leads to an increase in flow stress, then the thermal effects of the plastic work lead to shear localization. Such terms as thermoplastic shear instability are now in current use to describe these phenomena. ${ }^{14}$

Conceptually, if the effects of microstructure (i.e. inclusion count, presence of micro-cracks, and so forth) are ignored, the effects of strain rate and temperature in the torsion test are straightforward. For a given material, testpiece geometry, and applied strain rate, the rate of strain hardening will eventually be balanced by the rate of thermal softening; this corresponds to $\mathrm{d} \tau=0$. After this critical point, plastic flow will continue in a localized manner, often along a small number of shear bands. ${ }^{13}$ If the strain rate is decreased, the shear band width will increase. In the limit, for very slow tests, the width of the shear band will approach the gauge length of the specimen, i.e. shear-band localization will be suppressed until much higher strains. A theory of thermal shear banding has recently been developed, ${ }^{14}$ and it is the purpose of this paper to discuss this theory in relation to observations of shear bands in torsion tests.

\section{Theory}

For simple shear, by taking strain rate, the heat resulting from plastic work, and thermal conductivity into account, Bai's approximate model ${ }^{14}$ gives

$$
\left.\begin{array}{l}
\rho \frac{\partial^{2} \gamma}{\partial t^{2}}=\frac{\partial^{2} \tau}{\partial y^{2}} \\
K \tau \frac{\partial \gamma}{\partial t}=\rho c_{\mathrm{V}} \frac{\partial T}{\partial t}-\lambda \frac{\partial^{2} T}{\partial y^{2}}
\end{array}\right\}
$$

where the nomenclature is as given in the 'List of symbols'. The constant $K$, denoting that portion of the plastic work converted into heat, is $\sim 0 \cdot 9$ (Ref. 15). The $y$-axis is taken to be normal to the shear band length. Considering disturbances of the form

$$
\gamma_{\mathrm{a}} \exp (\alpha t+i k y)
$$

it is possible to obtain the homogeneous equations

$$
\left.\begin{array}{l}
\rho \alpha^{2} \gamma_{\mathrm{a}}+k^{2} \tau_{\mathrm{a}}=0 \\
K \tau_{0} \alpha \gamma_{\mathrm{a}}+k \dot{\gamma}_{0} \tau_{\mathrm{a}}-\left(\rho c_{\mathrm{V}} \alpha+\lambda k^{2}\right) T_{\mathrm{a}}=0
\end{array}\right\}
$$


where the subscripts 0 and a represent the basic state and the amplitude of the disturbance, respectively.

Assuming the constitutive equation has the form $\tau=\tau(\gamma, \dot{\gamma}, T)$, and using the identities

$$
Q=\left.\frac{\partial \tau}{\partial \gamma}\right|_{0} \quad P=-\left.\frac{\partial \tau}{\partial T}\right|_{0} \quad R=\left.\frac{\partial \tau}{\partial \dot{\gamma}}\right|_{0},
$$

the spectral equation of $\alpha$ (taken by equating the determinant of equations (2) to zero) is

$$
\begin{aligned}
& \rho^{2} c_{\mathrm{V}} \alpha^{3}+\left[K P \dot{\gamma}_{0}+\left(\lambda+c_{\mathrm{V}} R\right) k^{2}\right] \alpha^{2} \\
& \quad+\left(\lambda R k^{2}+\rho c_{\mathrm{V}} Q-k \tau_{0} P\right) k^{2} \alpha+\lambda Q k^{4}=0
\end{aligned}
$$

For all possible disturbances $(0<k<\infty), \alpha>0$ if $Q>0$, as long as

$$
\frac{K \tau_{0} P}{\rho c_{\mathrm{v}} Q}>1+2\left(\frac{K \lambda P \dot{\gamma}_{0}}{\rho c_{\mathrm{v}}^{2} Q}\right)^{1 / 2}
$$

This is the condition under which the disturbances would develop with increasing time.

Generally, shear bands are examined in post-mortem testpieces. For example, they can be identified as whiteetching lines of martensite in steels, and narrow bands in other materials. The shear bands observed in post-mortem samples are obviously representative of a late stage in their evolution and, as such, can be compared with the corresponding theory. Referring to the second of equations (1): as $t \rightarrow \infty$, this reduces to

$$
K \tau \dot{\gamma} \approx \lambda \frac{\partial^{2} T}{\partial y^{2}}
$$

An estimate of the term $\lambda\left(\partial^{2} T / \partial y^{2}\right)$ within a shear band is

$$
\lambda \frac{\partial^{2} T}{\partial y^{2}} \approx \lambda\left(\frac{T_{*}-T_{\mathrm{c}}}{\delta^{2}}\right)
$$

Usually, $T_{\mathrm{c}}$ is significantly lower than $T_{*}$; therefore, it is possible to make the approximation $\Delta T \approx T_{*}$.

Substituting these simplifications into equation (5) gives

$$
\delta \approx\left(\frac{\lambda T_{*}}{\tau_{*} \dot{\gamma}_{*}}\right)^{1 / 2}
$$

where the subscript $*$ denotes characteristic quantities within the band. Equation (5) appears to be physically reasonable, because an increase in thermal conductivity $\lambda$ and a decrease in the plastic-work rate would both tend to increase the band width.

\section{Comparison of theory with experiments}

Although the torsion test is of fundamental significance and is often used, it is surprising that very few researchers concerned with shear bands have actually measured the widths of bands obtained experimentally.

Lindholm et al. ${ }^{16}$ carried out torsion tests at strain rates between 0.009 and $330 \mathrm{~s}^{-1}$ on OFHC copper. At strain rates $\leqslant 9 \cdot 6 \mathrm{~s}^{-1}$, no maxima were observed in the stressstrain curves, whereas for tests at strain rates between 174 and $330 \mathrm{~s}^{-1}$, maxima were observed at shear strains of $\sim 5$. Metallographic sectioning showed that for tests at the lower strain rates the specimen gauge length remains uniformly deformed. For tests at the higher rates, however, shear bands $0.34 \mathrm{~mm}$ in width were observed, irrespective of strain rate.

Costin et al. ${ }^{17}$ conducted a number of torsion tests on two steels at different temperatures and strain rates. One steel was hot rolled, the other cold rolled. The cold-rolled steel showed shear banding at a strain rate of $500 \mathrm{~s}^{-1}$, where the shear bands were $\sim 0.19 \mathrm{~mm}$ in width. At quasistatic rates, the cold-rolled steel only exhibited uniform deformation. Irrespective of rate, the hot-rolled steel did not exhibit banding. These results were explained in terms of the differences in the strain-hardening capacity of the two steels.

Some other experimental observations of shear band widths, obtained under different loading conditions and for various materials, are listed in Table 1.

Using equation (7), it is possible to predict the shear band width of a given material if the appropriate material parameters, such as the coefficient of thermal conductivity and the stress state, are known. Moreover, besides the coefficient of thermal conductivity, the band temperature $T_{*}$ and shear stress $\tau_{*}$ may also correspond to material parameters; at least this will be so for a transformation band. In a transformation band, the temperature $T_{*}$ is approximately the melting or transformation temperature, while $\tau_{*}$ is of the order of the flow stress. ${ }^{23}$ The problem is whether there is a certain characteristic strain rate corresponding to $\dot{\gamma}_{*}$ for a given material. At high strain rates the viscosity of the material may become important. If this is so, then $\dot{\gamma}_{*} \approx \tau_{*} / \eta$, and equation (7) becomes

$$
\delta=\tau_{*}^{-1}\left(\lambda \eta T_{*}\right)^{1 / 2}
$$

From this equation, it can be concluded that the thermoplastic shear band width should be a material characteristic and that it should be fairly insensitive to details of the loading conditions. Materials data required for the calculation of bandwidths are given in Table 2, in which, for simplicity, the melting temperature $T_{\mathrm{M}}$ is used instead of the transformation temperature for estimating $\delta$ from equation (8). Typical measurements of shear band widths in copper and steel are, respectively, 0.34 (Ref. 16) and $0.19 \mathrm{~mm}$ (Ref. 17). The corresponding predicted values are 0.44 and $0.1 \mathrm{~mm}$, which are reasonably close approximations to the experimental widths, particularly since they are calculated using such a simple expression as equation (8).

It is interesting to note that the calculated bandwidths are larger than most of those given in Table 1 . The reason for this is most probably that the observed widths are usually those of transformed bands, which are the central part of the shear band only. The apparent insensitivity of shear band width to loading conditions, as shown by equation (8), is in good agreement with the observations of Backman and Finnegan. ${ }^{18}$ They found that the bandwidth depends more on the material than on the loading conditions (for example, impact velocity). Moreover, Backman and Finnegan found that there was little

Table 1 Reported observed shear band widths

\begin{tabular}{llll}
\hline $\begin{array}{l}\text { Shear band width, } \\
\mathrm{mm}\end{array}$ & Materials & Loading condition(s) & Ref. \\
\hline $0.003-0.01$ & Various materials, including steel & High-velocity impact & 18 \\
$0.0033-0.0114$ & Fe-Ni-C alloys & & 19 \\
$0.01-0.03$ & Low-carbon high-strength pipe steel & Normal and tangential impacts & 20 \\
$0.01-0.03$ & Ti, steels, and uranium alloys & Dynamic expansion of shells & 21 \\
0.03 & Ni-Cr steel & Punching with explosives & 22 \\
$0.005-0.2$ & Rolled steel & Penetration, exploding & 23 \\
& & cylinders, etc. & 23 \\
\hline
\end{tabular}


40. Dodd and Bai Width of adiabatic shear bands

Table 2 Materials parameters and predicted shear band widths $2 \delta$

\begin{tabular}{lllll}
\hline & $\mathrm{Al}$ & $\mathrm{Cu}$ & Mild steel & Ref. \\
\hline$\tau_{\mathrm{f}}, \mathrm{MN} \mathrm{m}^{-2}$ & $\sim 300$ & $\sim 200$ & $\sim 300$ & 24 \\
$T_{\mathrm{M}}, \mathrm{K}$ & $775-877$ & 1355 & 1800 & 25 \\
$\lambda_{273 \mathrm{~K}, \mathrm{~W} \mathrm{~m} \mathrm{~N}^{-1} \mathrm{~K}-1}$ & 236 & 403 & 50 & $\ldots$ \\
$\eta, \mathrm{kPa} \mathrm{s}$ & $2 \cdot 1$ & $3 \cdot 6$ & $2 \cdot 8,2 \cdot 1$ & 26 \\
$2 \delta, \mathrm{mm}$ & 0.136 & 0.444 & $0 \cdot 106$ & $\cdots$ \\
\hline
\end{tabular}

variation in bandwidth for impact velocities between 0.5 and $3 \cdot 2 \mathrm{~km} \mathrm{~s}^{-1}$.

\section{Conclusions}

An equation for the half-width of an adiabatic shear band has been derived in terms of the coefficients of thermal conductivity and viscosity, the band temperature, and the flow stress. Despite the simplifications inherent in the derivation of this equation, it gives adequate predictions when compared with experiment. However, much more experimental work is required. Particularly necessary are measured shear band widths in various materials tests at different strain rates.

\section{References}

1. A. NADAI: 'Plasticity'; 1931, New York, McGraw-Hill.

2. B. DODD and A. G. ATKINS: Acta Metall., 1983, 13, 9.

3. R. S. CULVER: in 'Metallurgical effects at high strain rates', (ed. R. W. Rhode et al.), 519; 1973, London, Plenum.

4. G. R. JOHNSON, J. M. HOEGFELDT, U. S. LINDHOLM, and A. NAGY: J. Eng. Mater. Technol. (Trans. ASME H), 1983, 105, 42.

5. C. ZENER and J. H. HOLLOMON: J. Appl. Phys., 1944, 15, 22.
6. R. F. RECHT: J. Appl. Mech. (Trans. ASME E), 1964, 86, 189.

7. K. C. DAO and D. A. SHOCKLEY: J. Appl. Phys., 1979, 50, 8244.

8. w. JOHNSON: 'Impact strength of materials'; 1972, London, Edward Arnold.

9. I. M. HUTCHINGS: in 'Material behavior under high stress and ultra-high loading rates', 29th Sagamore Army Materials Research Conf., 161-196; 1982, New York, Plenum.

10. W. JOHNSON, G. L. BARAYA, and R. A. C. SLATER: Int. J. Mech. Sci., 1964, 6, 409.

11. R. A. C. SLATER: Proc. Manch. Assoc. Eng., 1965-1966, 1-45.

12. A. J. BEDFORD, A. L. WINGROVE, and K. R. L. THOMPSON: $J$. Austr. Inst. Met., 1974, 19, 61.

13. H. C. ROGERS: Ann. Rev. Mater. Sci., 1979, 9, 283; see also 'Adiabatic shearing - a review', Drexel University, Philadelphia, $\mathrm{Pa}, 1974$.

14. Y. L. BAI: J. Mech. Phys. Solids, 1982, 30, 195.

15. G. I. TAYlOR and H. QUINNEY: Proc. R. Soc., 1934, A413, 307.

16. U. S. LINDHOLM, A. NAGY, G. R. JOHNSON, and J. M. HOEGFELDT: J. Eng. Mater. Technol. (Trans. ASME H), 1980, 102, 376.

17. L. S. COSTIN, E. E. CRISMAN, R. H. HAWLEY, and J. DUFFY: in 'Mechanical properties at high rates of strain', Inst. Phys. Conf. Ser., no. 47, (ed. J. Harding), 90; 1979, London, Institute of Physics.

18. M. E. BACKMAN and S. A. FINNEGAN: in 'Metallurgical effects at high strain rates', (ed. R. W. Rhode et al.), 531; 1973, London, Plenum.

19. R. J. RUSSELl and P. G. WINChELL: Metall. Trans., 1972, 3, 2403.

20. F. S. JEGLIC and R. H. PACKWOOD: Metallography, 1978, 11, 43.

21. M. STELLY: in 'Mechanical properties at high rates of strain', Inst. Phys. Conf. Ser., no. 47, (ed. J. Harding), 252; 1979, London, Institute of Physics.

22. G. L. MOSS: in 'Shock waves and high-strain-rate phenomena', (ed. M. A. Meyers and L. E. Murr), 299; 1981, London, Plenum.

23. L. SEAMAN: 'Shear bands: observations and experiments', Lecture presented at Beijing Institute of Technology, Sept. 1983.

24. U. S. LINDHOLM and G. R. JOHNSON: in 'Material behavior under high stress and ultra-high loading rates', 29th Sagamore Army Materials Research Conf., 61-79; 1982, New York, Plenum.

25. J. D. CAMPBell: Mater. Sci. Eng., 1973, 12, 3.

26. A. D. SAKHAROV, R. M. ZAIDEL, V. I. MINEEV, and A. G. OLEINIK: Dokl. Akad. Nauk. SSSR, 1964, 159, 1019.

\section{HEAT TREATMENT SHANGHAl '83

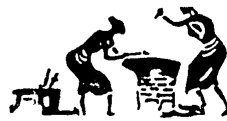 \\ 1983.11 上}

Proceedings of the Third International Congress on Heat Treatment of Materials, 7-11 November 1983. Shanghai, organized by the Heat Treatment Institution of the Chinese Mechanical Engineering Society and the International Federation for the Heat Treatment of Materials.

Edited by Professor T. Bell

$297 \times 210 \mathrm{~mm}$ Casebound $532 p p$

The abridged proceedings of the Third International Congress on Heat Treatment of Materials, organized by the Heat Treatment Institution of the Chinese Mechanical Engineering Society in cooperation with the IFHT, held in Shanghai on 7-11 November 1983, is now available. This volume, edited by Professor T. Bell, includes papers dealing with physical metallurgy, ferritic and austenitic thermochemical treatment quality control and equipment, controlled atmospheres, coatings, energy management, and high energy techniques.

Order code: 192.

Price: UK f48 (members f38.40). Overseas US\$96 (members $\$ 76 \cdot 80$ ).

Remittance with order to:

The Institute of Metals

Subscriber Services Department

1 Carlton House Terrace

London SW1Y 5DB 